УДК 911:8:574.24:519.876:574.21:582.635.1

ЗАКОНОМЕРНОСТИ ФИТОИНДИКАЦИИ ЗАГРЯЗНЕНИЙ ГОРОДСКОЙ СРЕДЫ МАКСИМАЛЬНОЙ ШИРИНОЙ ЛИСТЬЕВ БЕРЕЗЫ ПОВИСЛОЙ

\author{
Мазуркин П.М., Кудряшова А.И. \\ Поволжский государственный технологический университет, Йошкар-Ола, \\ e-mail:kaf_po@mail.ru,Little-one7@yandex.ru
}

\begin{abstract}
Предлагаются индикаторы в виде групп из не менее 10 растущих в течение вегетационного периода учетных листьев березы повислой, отобранных и помеченных белой ниткой со стороны преобладающих ветров. Ранее были получены закономерности поведения листьев в вегетационный период от момента распускания почек дерева до опадения каждого учетного листа. Предложена методика измерения ширины листьев березы повислой в вегетационный период. Было получено, что до достижения максимума длины, ширины, периметра и площади учетных листьев при не менее чем 10 измерениях за сезон закономерности изменяются по нарастающей ветви биотехнического закона. Поэтому летом 2018 г. были проведены измерения в г. Йошкар-Оле, начиная с 15 июля до максимума ширины листа, как наиболее удобного для измерения параметра учетного листа. Оказалось, что максимум ширины листа зависит от условий произрастания дерева. Цель - выявление закономерностей фитоиндикации измерениями ширины листьев березы повислой во времени вегетационного периода около максимума роста листа с концентрациями диоксида серы и углерода, уровню радиоактивного фона в различных точках возле автомобильных дорог с наибольшими загрязнениями. Получены закономерности влияния этих видов загрязнения на среднюю максимальную ширину и времени вегетации с 1 мая 2018 г. до максимума ширины учетного листа. Оказалось, что даже в экологически чистом городе (10 место по России) малые концентрации, примерно в 25 раз меньше ПДК, оказывают сильное влияние на параметры роста и развития листьев березы повислой. Вначале с увеличением концентрации трех химических веществ на восьми точках городской среды оказывают благоприятное влияние на вегетацию листьев. При дальнейшем увеличении концентрации происходит сильное торможение роста и развития листьев. Предлагаемая методика рекомендуется для школьных экологических кружков.
\end{abstract}

Ключевые слова: городская среда, загрязнения, листья березы, вегетация, ширина, закономерности

\title{
PATTERNS OF PHYTOINDICATION POLLUTION OF THE URBAN ENVIRONMENT THE MAXIMUM WIDTH OF THE LEAVES OF THE SILVER BIRCH
}

\author{
Mazurkin P.M., Kudryashova A.I. \\ Volga State University of Technology, Yoshkar-Ola, e-mail: kaf_po@mail.ru, Little-one7@yandex.ru
}

\begin{abstract}
We offer indicators in the form of groups of at least 10 accounting leaves growing during the growing season, selected and marked with a white thread of birch hanging from the prevailing winds. Was previously obtained regularities in the behavior of leaves in the vegetation period from the date of Bud wood to the subsidence of each account sheet. The method of measuring the width of birch leaves in the growing season is proposed. It was found that before reaching the maximum length, width, perimeter and area of leaves with at least 10 measurements per season, the patterns vary along the growing branch of the biotechnical law. Therefore, in the summer of 2018 , measurements were carried out in the city of Yoshkar-Ola, starting from July 15 to the maximum width of the sheet, as the most convenient for measuring the parameter of the accounting sheet. It turned out that the maximum width of the sheet depends on the growing conditions of the tree. The aim is to identify the patterns of phytoindication by measuring the width of birch leaves hanging during the growing season near the maximum concentration of sulfur dioxide and carbon, the level of radioactive background at various points near the roads with the greatest pollution. The regularities of the influence of these types of pollution on the average maximum width and vegetation time from may 1, 2018 to the maximum width of the registration sheet are obtained. It turned out that even in an ecologically clean city (10th place in Russia), low concentrations are about 25 times less than MPC, have a strong influence on the growth and development of birch leaves. Initially, with an increase in the concentration of three chemicals at eight points of the urban environment have a beneficial effect on the vegetation of leaves. With further increase in concentration there is a strong inhibition of growth and development of leaves. The proposed method is recommended for school environmental groups.
\end{abstract}

Keywords: urban environment, pollution, birch leaves, vegetation, width, patterns

В инженерной экологии широко проводилось изучение свойств растений как индикаторов экологических условий [1].По мнению [2], для оценки состояния окружающей городской среды необходимо изучение взаимодействия различных факторов. В окружающую среду поступает все большее количество загрязняющих веществ [3].

Часть этих веществ использует растительность, и, как правило, из-за многих видов ан- тропогенных загрязняющих веществ понижается её продуктивность. Это происходит из-за того, что растения адаптировались к очень медленно изменяющемуся видовому разнообразию загрязнений. В особенности растения не приспособлены к быстро меняющимся концентрациям новых видов загрязнения, вызванных человеческой деятельностью.

При этом вегетационный период становится одним из важных параметров меха- 
низма адаптации растений к окружающей среде, так как развитие листьев весьма чувствительно к изменениям погоды и загрязнениям. В этой связи особенно перспективно следить за поведением железистых волосков на поверхности листьев березы повислой [4]. Листья производят их в течение всего вегетационного периода, и они являются наименьшими элементами листьев.

Однако из-за сложности изучения волосков мы приняли за объект исследования листья деревьев по патентам на изобретения 2597643, 2597645, 2606189 и 2615363.

Главным объектом глобального и локального экологического мониторинга может стать береза с учетными листьями без их срезания $[5,6]$. Березняки северного полушария (Голарктическое царство по А.Л. Тахтаджяну [7]) занимают Северное полушарие вдоль Ледовитого океана. Модели с волновыми составляющими нами были получены на учетных листьях березы, произрастающих в разных экологических условиях. Доказано, что загрязнение воздуха снижает колебательную адаптацию листьев в процессе онтогенеза. С повышением загрязненности воздуха максимум роста листьев достигается раньше.

В статье показаны закономерности фитоиндикации измерениями ширины листьев березы повислой во времени вегетационного периода около максимума роста в зависимости от концентраций диоксида серы и углерода, а также от уровня радиоактивного фона в различных точках возле автомобильных дорог с наибольшими загрязнениями.

\section{Материалы и методы исследования}

Согласно сведениям [8], в г. Йошкар-Оле в рейтинге пород деревьев береза повислая оказалась на третьем месте вследствие высадок по сторонам улиц в конце семидесятых годов. В особенности стремились озеленить ею центральные улицы города.

По фактическим данным содержания диоксида серы и углерода, а также уровню радиоактивного фона, на улицах г. Йошкар-Олы отмечено, что концентрация диоксида серы в атмосферном воздухе города не превышала ПДК (0,5 мг/м³). Фактическая концентрация диоксида углерода на различных улицах города изменялась в пределах от 0,01 до 0,04\% от ПДК. Как показали результаты исследований, радиоактивный фон варьировался в пределах от

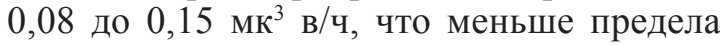
естественного фона [9].
Наши исследования показали, что даже при таких низких концентрациях загрязнения листья березы значительно изменяются по метрическим параметрам, поэтому они могут быть приняты за индикаторы экологического состояния в различных точках городской среды.

В наших патентах на изобретения 2597643, 2597645, 2606189 и 2615363 приведены закономерности поведения листьев за вегетационный период от момента распускания почек дерева до опадения каждого учетного листа. Было получено, что на стадии роста от распускания почек до достижения максимума длины, ширины, периметра и площади учетных листьев, при не менее чем 10 измерениях за сезон, закономерности изменяются по нарастающей ветви биотехнического закона.

В отличие от патента 2606189 [10], измерения ширины листа (рис. 1) удобней, и поэтому предлагается применять их при сравнении мест произрастания берез около автомобильных дорог с интенсивным движением с учетом преобладающих ветров и источников загрязнения в различных экологических условиях города. При этом другие параметры листа (длина, площадь и периметр) в зависимости от времени вегетационного периода с момента распускания почек изменяются почти аналогичным образом.

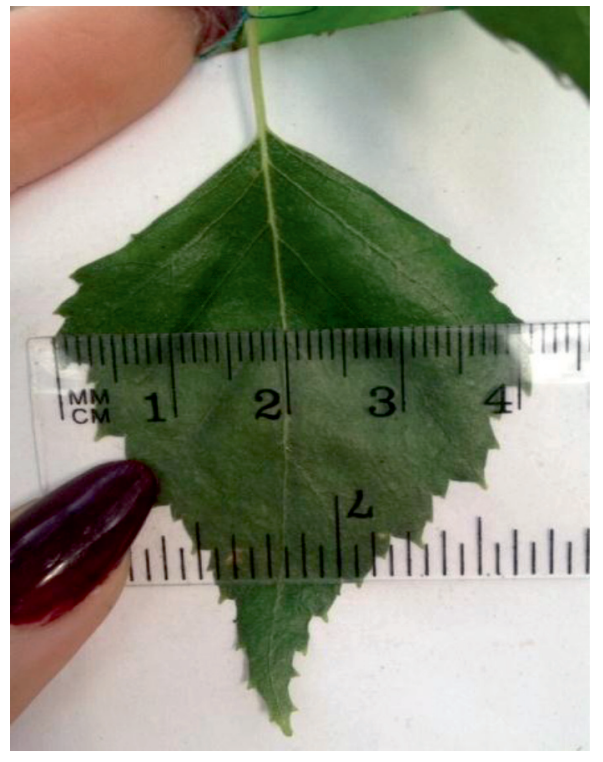

Рис. 1. Измерения ширинь листа

На лист кладут прозрачную линейку так, чтобы линия метки какой-то цифры в сантиметрах располагалась с осью продоль- 
ной жилки листа. На рис. 1 жилка совпала с линией метки 2 см. Затем лист с линейкой фотографируют цифровым фотоаппаратом с функцией хранения фотоснимков. На компьютере фото листа обрезают с помощью кнопки «Обрезка», затем увеличивают для точного подсчета ширины до формата А4.

Для многократных измерений каждый учетный лист помечали белой ниткой с биркой с номером, привязанной к черешку у основания листа.

Эксперименты проведены в экологически чистом городе Йошкар-Оле (10-е место в рейтинге по России) [1] в различных точках возле автомобильных дорог с наибольшими загрязнениями. При этом учитывали направление преобладающего ветра, расстояние от дороги и высоту расположения группы листьев от поверхности почвы.

В таблице приведен фрагмент данных экспериментов с листьями березы.

В ней приняты следующие условные обозначения:

$\mathrm{SO}_{2}$ - изменение концентрации диокси-

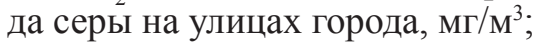

$\mathrm{CO}_{2}$ - изменение концентрации диокси-

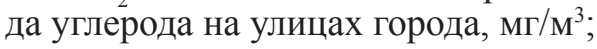

$R_{f}$ - изменение радиоактивного фона на улицах г. Йошкар-Олы, мкЗв/ч;

$\tau$ - время вегетации с момента распускания почек в 2018 г. с 1 мая до достижения максимального значения ширины листа, сутки;

$\bar{b}_{\max }$ - максимальная ширина листа за вегетационный период, мм.

Для удобства моделирования значения диоксида серы и диоксида углерода умножены на 100, а фактически, например на

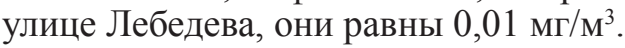

Влияющие переменные имеют малые интервалы изменения: диоксид серы от 0,01 до 0,03 мг/ $\mathrm{M}^{3}$; диоксид углерода от 0,01 до

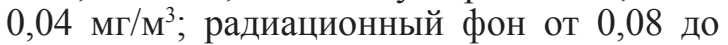
0,16 мк $^{3}$ в/ч. Два зависимых показателя изменяются так: время вегетации от 91 до 110 суток; максимальная ширина листа от 39,56 до 48,66 мм.

Тренд образуется при условии, когда период колебания стремится к бесконечности [7-9]. Все модели в данной статье были выявлены по двучленной формуле

$$
y=\operatorname{aexp}\left(-b x^{c}\right)+d x^{e} \exp \left(-f x^{g}\right),
$$

где $y$ - зависимый показатель, $x$ - влияющая переменная, $a-g$ - параметры модели (1), идентифицируемые в программной среде CurveExpert-1.40.

Первый член является модифицированным законом Лапласа (в математике), Мандельброта (в физике), Перла - Ципфа (в биологии) и Парето (в эконометрике), а второй - биотехническим законом $[5,6]$.

\section{Результаты исследования и их обсуждение}

Летом 2018 г. были проведены измерения в г. Йошкар-Оле, начиная с 15 июля до максимума роста листа по ширине примерно до конца августа. Оказалась, что максимум ширины листа зависит от условий произрастания дерева и меняется от начала вегетации 1 мая в течение 92-110 суток. Эта высокая изменчивость $(110$ - 92) / $92=19,57 \%$ позволяет время вегетации использовать как индикатор поведения листьев березы.

Получены закономерности влияния концентраций диоксидов серы и углерода, а также уровня радиоактивного фона на среднюю максимальную ширину и времени вегетации с 1 мая 2018 г. до достижения максимума ширины учетного листа.

Сопоставление загрязнений городской среды с максимальной шириной листьев березы повислой во времени вегетационного периода

\begin{tabular}{|c|c|c|c|c|c|}
\hline \multirow{2}{*}{$\begin{array}{c}\text { Место произрастания } \\
\text { учетной березы }\end{array}$} & \multicolumn{3}{|c|}{ Виды загрязнения } & \multirow{2}{*}{$\begin{array}{c}\text { Время } \\
\text { вегетации } \\
\tau, \text { сутки }\end{array}$} & \multirow{2}{*}{$\begin{array}{c}\text { Максимальная } \\
\text { ширина листа, } \\
\bar{b}_{\max }, \text { мм }\end{array}$} \\
\hline & $\begin{array}{c}\mathrm{SO}_{2} \\
10^{-2} \mathrm{M} \Gamma / \mathrm{M}^{3}\end{array}$ & $\begin{array}{c}\mathrm{CO}_{2} \\
10^{-2} \mathrm{M} \Gamma / \mathrm{M}^{3}\end{array}$ & $\begin{array}{c}\text { Рад. фон } \\
R_{f}, \mathrm{MK}^{3} \mathrm{~B} / \mathrm{ч}\end{array}$ & & \\
\hline Ул. Лебедева & 1 & 1 & 0,08 & 110 & 45,92 \\
\hline Воскресенский пр-т & 2 & 2 & 0,10 & 110 & 48,66 \\
\hline Ул. Эшкинина & 4 & 3 & 0,10 & 92 & 39,77 \\
\hline Пр-т Ленина & 3 & 3 & 0,12 & 99 & 40,11 \\
\hline Б-р Чавайна & 2 & 2 & 0,12 & 106 & 44,71 \\
\hline Ул. Панфилова & 3 & 3 & 0,14 & 103 & 39,56 \\
\hline Ул. Карла Маркса & 3 & 4 & 0,16 & 99 & 44,39 \\
\hline Ул. Строителей & 5 & 4 & 0,16 & 103 & 42,25 \\
\hline
\end{tabular}


На рис. 2 показаны графики влияния концентрации диоксида серы $\mathrm{SO}_{2} \rightarrow \tau$ на время вегетации листьев березы и $\mathrm{SO}_{2} \rightarrow \bar{b}_{\max }$ на максимальную ширину листа.

Влияние концентрации диоксида серы на время вегетации

$$
\tau=109,07953 \exp \left(0,36575 \mathrm{SO}_{2}^{2,11956}\right)-3,14298 \mathrm{SO}_{2}{ }^{2,66043} .
$$

Влияние концентрации диоксида серы на максимальную ширину листа

$$
\bar{b}_{\text {max }}=0,08466 \exp \left(6,32267 \mathrm{SO}_{2}^{4,26871}\right)-5,79832 \cdot 10^{7} \mathrm{SO}_{2}^{9,53251} \exp \left(-17,69806 \mathrm{SO}_{2}^{0.323017}\right) \text {. }
$$

Первый член по модифицированному закону Лапласа показывает экспоненциальный рост зависимых показателей с увеличением концентрации диоксида серы. Но этой тенденции противодействует негативное (отрицательный знак перед второй составляющей) воздействие этого вида загрязнения. При этом на время вегетации негативное влияние происходит по показательному закону, а на максимальную ширину листа с некоторым торможением - по биотехническому закону. Как видно из графиков на рис. 2 , до концентрации 0,014 мг/кг рост концентрации диоксида серы даже повышает зависимые показатели, то есть до этой концентрации диоксид серы положительно сказывается на жизнедеятельности листьев березы.

На рис. 3 показаны графики влияния концентрации диоксида углерода $\mathrm{CO}_{2} \rightarrow \tau$ на время вегетации листьев и $\mathrm{CO}_{2} \rightarrow \bar{b}_{\max }$ на максимальную ширину листа.

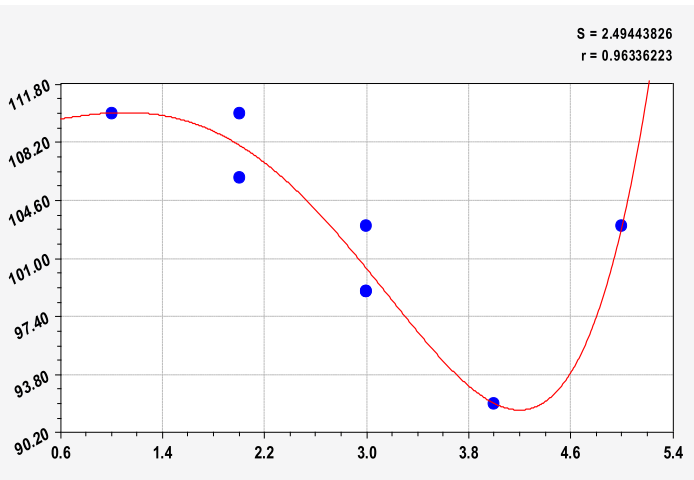

На время вегетации

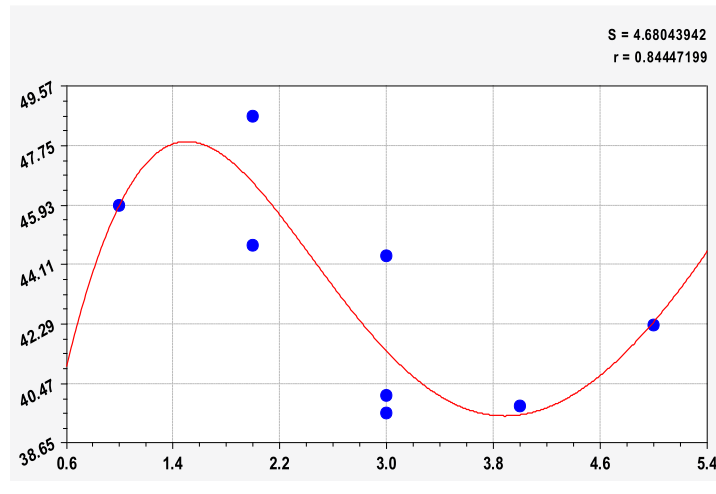

На максимальную ширину листа

Рис. 2. График влияния концеентрациии диоксида серь

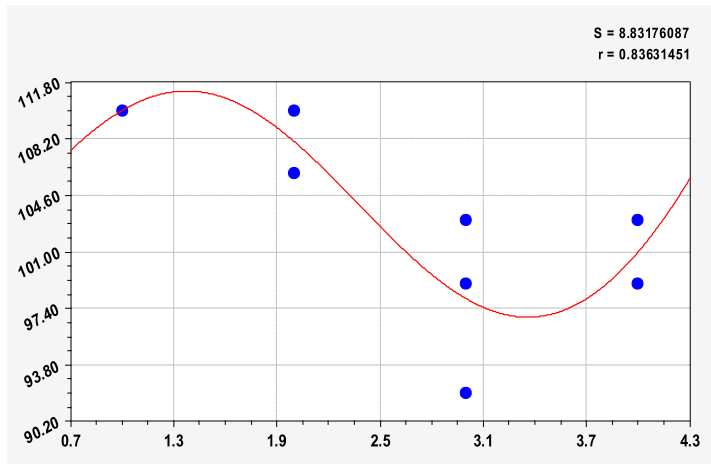

На время вегетации

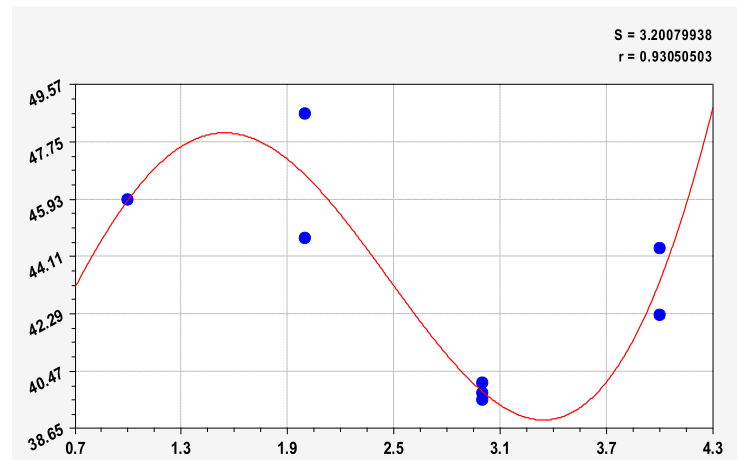

На максимальную ширину листа

Рис. 3. График влияния концентрации диоксида углерода 
Влияние концентрации диоксида углерода на время вегетации

$$
\tau=97,54959 \exp \left(0,13322 \mathrm{CO}_{2}^{0,80153}\right)-2,11224 \mathrm{CO}_{2}^{4,35819} \exp \left(-0,37548 \mathrm{CO}_{2}^{1,49377}\right)
$$

Влияние концентрации диоксида углерода на максимальную ширину

$$
\bar{b}_{\max }=35,16704 \exp \left(0,310709 \mathrm{CO}_{2}^{0,99992}\right)-4,48249 \mathrm{CO}_{2}^{4,30896} \exp \left(-0,77667 \mathrm{CO}_{2}^{1,00081}\right) .
$$

Обе формулы по конструкции одинаковы и имеют по два одинаковых члена.

До рационального значения примерно 0,015 мг/кг диоксид углерода положительно влияет на рост и развитие учетных листьев березы повислой.

С повышением содержания диоксида серы и углерода модифицированный закон Лапласа растет, а по второму члену с отрицательным знаком происходит снижение, время вегетации сдвигается к началу онтогенеза. Для условия роста и развития листа лучшей оказались улица Лебедева и Воскресенский проспект, а худшей - улица Эшкинина.

На рис. 4 показаны графики влияния радиоактивного фона $R_{f} \rightarrow \tau$ на время вегетации листьев и $R_{f} \rightarrow \bar{b}_{\max }$ на максимальную ширину листа.

Влияние радиоактивного фона на время вегетации определяется формулой

$$
\tau=1,54079 \cdot 10^{5} \exp \left(-11,05799 R_{f}^{0,37244}\right)-1,06089 \cdot 10^{5} R_{f}^{0,1994} \exp \left(-13,28765 R_{f}^{0,52879}\right) .
$$

Влияние радиоактивного фона на максимальную ширину листа

$$
\bar{b}_{\max }=46,27237 \exp \left(72695,278 R_{f}{ }^{6,35945}\right)-1,0415106 R_{f}^{5,50019} .
$$

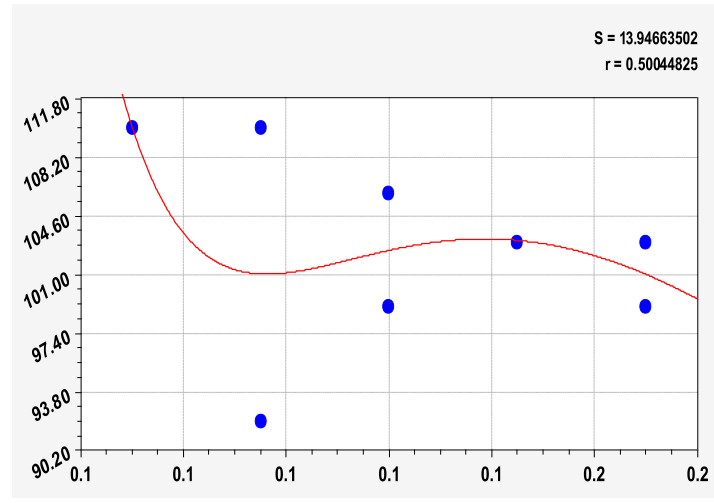

На время вегетации

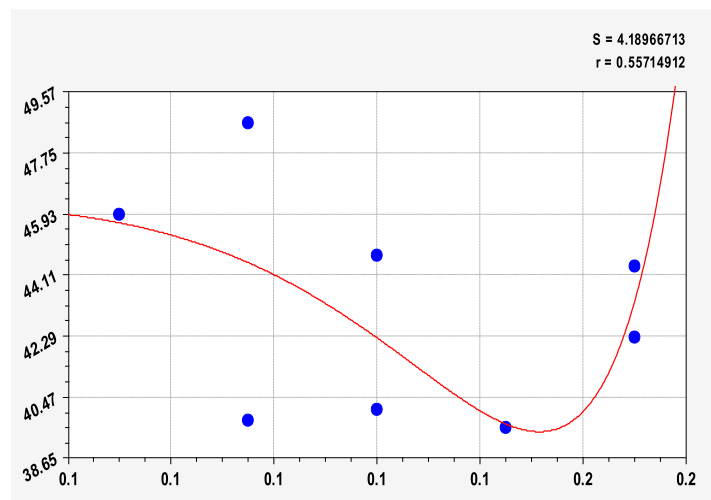

На максимальную ширину листа

Рис. 4. График влияния радиоактивного фона

Радиоактивный фон влияет неоднозначно: время вегетации снижается и по первому члену формулы (6); максимальная ширина листа, независимо от экспоненциального роста по первому члену уравнения (7), из-за негативного влияния второго члена по показательному закону также снижается.

С дальнейшим ростом радиоактивного фона условия произрастания листьев ухудшаются, имеют большой разброс, закономерности получаются с очень малыми коэффициентами корреляции (средняя сила факторной связи), поэтому нужны дополнительные исследования.
На основе проведенных теоретических и экспериментальных исследований сформулированы основные научные выводы.

Методика измерения ширины листьев в вегетационный период рекомендуется для школьных экологических кружков при наблюдениях за ростом и развитием листьев деревьев в городских парках, аллеях, придорожных полосах.

Измерениями ширины учетных листьев березы повислой в вегетационный период, отобранных и помеченных белой ниткой со стороны преобладающих ветров, можно выявлять закономерности фитоиндикации 
в зависимости от концентраций диоксида серы и углерода, а также уровня радиоактивного фона в различных точках возле автомобильных дорог.

В экологически чистом городе ЙошкарОле имеются малые концентрации загрязнителей примерно в 25 раз меньше ПДК, но они оказывают сильное влияние на параметры роста и развития листьев березы повислой. Вначале с увеличением концентрации химические вещества, на восьми точках городской среды, до некоторого уровня оказывают благоприятное влияние на вегетацию листьев. Но с дальнейшим увеличением концентрации происходит сильное угнетение и торможение роста и развития листьев.

Первый член по модифицированному закону Лапласа показывает экспоненциальный рост зависимых показателей с увеличением концентрации диоксида серы. Но этой тенденции противодействует негативное (отрицательный знак перед второй составляющей) воздействие этого вида загрязнения. До концентрации 0,014 мг/кг рост концентрации диоксиды серы даже повышает зависимые показатели, то есть до этой концентрации диоксида серы положительно сказывается на жизнедеятельность листьев березы.

С повышением содержания диоксида серы и диоксида углерода по модифицированному закону Лапласа ширина листа растет, а по второму члену с отрицательным знаком происходит снижение ширины, при этом время вегетации сдвигается к началу онтогенеза.

Радиоактивный фон влияет неоднозначно: время вегетации снижается и по первому члену формулы; максимальная ширина листа, независимо от экспоненциального роста по первому члену уравнения, из-за негативного влияния второго члена по показательному закону, также снижается. В итоге любое значение радиоактивного фона влияет негативно на развитие и рост листьев березы повислой.

Приведенные формулы можно идентифицировать и в условиях других городов, где произрастает береза повислая. На первый год необходимо проводить сравнения химических и иных загрязнений с ростом листьев на стадии роста в вегетационный период. Для сопоставления идентифицируются закономерности научными работниками. Затем со второго года методикой фитоиндикации уже могут пользоваться школьники без трудоемких и дорогостоящих измерений концентрации загрязнителей. При этом достаточно определить время роста учетных листьев с начала распускания почек без выявления устойчивых закономерностей.

\section{Список литературы / References}

1. Понятие устойчивого развития. Национальное агентство устойчивого развития. [Электронный ресурс]. URL: http://green-agency.ru/ponyatie-istoriya-i-sfery-ustojchivogorazvitiya/ (дата обращения: 28.06.2019).

The concept of sustainable development. National Agency for Sustainable Development. [Electronic resource]. URL: http://green-agency.ru/ponyatie-istoriya-i-sfery-ustojchivogorazvitiya/ (date of access: 28.06.2019) (in Russian).

2. Кириллов С.Н., Половинкина Ю.С. Комплексная геоэкологическая оценка территории города Волгограда // Вестник Волгоградского государственного университета. Серия 3: Экономика. Экология. 2011. № 1 (18). С. 239-245.

Kirillov S.N., Polovinkina Yu.S. On Complex Geo-Ecological Evaluation of Volgograd Cityarea // Vestnik Volgogradskogo gosudarstvennogo universiteta. Seriya 3: Ekonomika. Ekologiya. 2011. № 1 (18). P. 239-245 (in Russian).

3. Кочуров Б.И. Экодиагностика и сбалансированное развитие: учеб. пос. М., Смоленск: Маджента, 2003. 384 с.

Kochurov B.I. Ecodiagnostics and Balanced Development: textbook. M., Smolensk: Magenta, 2003. 384 p. (in Russian).

4. 10 самых чистых городов России в 2019. [Электронный ресурc]. URL: http://top10a.ru/10-samyx-chistyx-gorodovrossii-v-2018-godu.html (дата обращения: 08.06.2019).

The 10 most clean cities in Russia in 2019. [Electronic resource]. URL: http://top10a.ru/10-samyx-chistyx-gorodovrossii-v-2018-godu.html (date of access: 08.06.2019) (in Russian).

5. Мазуркин П.М., Кудряшова А.И. Закономерности онтогенеза листьев деревьев. Динамика роста листьев липы и березы в чистой и загрязненной автомобильными выхлопами городской среде. LAP Lambert Academic Publishing, 2015. $108 \mathrm{c}$

Mazurkin P.M., Kudryashova A.I. Patterns of ontogenesis of tree leaves. The growth dynamics of linden and birch leaves in a clean and polluted automobile exhaust urban environment. LAP Lambert Academic Publishing, 2015. 108 p. (in Russian).

6. Мазуркин П.М., Кудряшова А.И. Динамика онтогенеза листьев дерева. Йошкар-Ола: ПГТУ, 2015. 172 с.

Mazurkin P.M., Kudryashova A.I. Dynamics of ontogenesis of tree leaves. Yoshkar-Ola: PGTU, 2015. 172 p. (in Russian).

7. Takhtajan A.L. Floristic regions of the world. University of California, 1986. $523 \mathrm{p}$.

8. Марышев В.M. Топ-10 самых распространенных видов деревьев Йошкар-Олы// Марийская правда. 26.05.2016 г. [Электронный pecypc]. URL: http://moyaokruga. ru/marpravda/Articles.aspx?articleId=67085 (дата обращения: 08.06.2019).

Maryshev V.M. Top 10 most common types of trees Yoshkar-Ola // Mariyskaya Pravda. 05.26.2016 [Electronic resource]. URL: http://moyaokruga.ru/marpravda/Articles. aspx? articleId=67085 (date of access: 08.06.2019). (in Russian).

9. Воскресенская О.Л., Воскресенский В.С., Старикова Е.А. Анализ экологической обстановки на улицах г. Йошкар-Олы по содержанию оксидов серы, углерода и уровню радиоактивного фона // Современные проблемы медицины и естественных наук: сборник статей Всероссийской научной конференции. Йошкар-Ола, 2018. С. 402-405.

Voskresenskaya O.L., Voskresenskiy V.S., Starikova Ye.A. Analysis of the environmental situation on the streets of Yoshkar-Ola on the content of sulfur oxides, carbon and the level of radioactive background // Sovremennyye problemy meditsiny i yestestvennykh nauk: sbornik statey Vserossiyskoy nauchnoy konferentsii. Yoshkar-Ola, 2018. P. 402-405 (in Russian).

10. Мазуркин П.М., Кудряшова А.И. Способ факторного анализа онтогенеза учетных листьев дерева // Патент РФ № 2606189. МПК G 01 D21 / 00(2006.01). Заявитель и патентообл. Мазуркин П.М. Заявка № 2015112149 от 03.04.2015. Опубл. 10.01.2017. Бюл. № 1. 